\title{
Talking to, Not About, Citizens: Experiences of Focus Groups in Public E-Service Development
}

\author{
Karin Axelsson and Ulf Melin
}

\section{Linköping University Post Print}

\section{Tweet}

N.B.: When citing this work, cite the original article.

Original Publication:

Karin Axelsson and Ulf Melin, Talking to, Not About, Citizens: Experiences of Focus Groups in Public E-Service Development, 2007, Electronic Government, 179-190.

ISBN: 978-3-540-74443-6 (print), 978-3-540-74444-3 (online)

http://dx.doi.org/10.1007/978-3-540-74444-3_16

From the 6th International Conference, EGOV 2007, Regensburg, Germany, September 3-7, 2007.

Copyright: Inderscience http://www.inderscience.com/ 


\title{
Talking to, not about, Citizens - Experiences of Focus Groups in Public E-Service Development
}

\author{
Karin Axelsson ${ }^{1}$, Ulf Melin ${ }^{1}$ \\ ${ }^{1}$ Department of Management and Engineering, Linköping university, SE-581 83 Linköping, \\ Sweden \\ \{karin.axelsson, ulf.melin\}@liu.se
}

\begin{abstract}
This paper focuses deficient understanding of citizens' needs regarding public e-services. In Sweden e-government efforts are motivated by dual goals of citizen benefit and agencies' internal efficiency. Rhetorical, this is a persuasive ambition, but in practice it seems to be easier to focus agency efficiency and redesign of business processes and information systems than to find out what citizens really want. Citizens, i.e. the future users of the e-service, are in best case represented in the project by citizen organizations. More seldom do individual citizens take part in the project. User needs are, thus, sometimes "guessed" instead of analyzed. We report from an e-government project which started with little understanding of the future users. To overcome this we introduced focus groups as a method to meet and talk to citizens and find out their needs regarding the e-service. The paper discusses how focus groups can be used in e-government projects.
\end{abstract}

Keywords: Focus groups, public e-services, e-service development, egovernment, web portal. 


\section{Introduction}

Most efforts concerning public e-service development have a dual goal of being both beneficial to citizens and increasing internal efficiency in the government agency. In Sweden, as in many other countries, the government has declared this duality of egovernment in many official documents. Rhetorical, the citizen benefits tend to be most emphasized in such statements. When studying e-service development projects, on the other hand, the increase of agency internal efficiency seems to be more accentuated. Some projects succeed in balancing these dual goals, but projects that tend to forget the "real citizens" as future users of the e-service are far from rare.

This problem of neglecting the users' needs and requirements can easily be related to user participation in other information systems development (ISD) projects. This is a well researched subject where a lot of scholars within the IS field as well as other related fields have studied the effects of user participation [e.g. 16, 18]. The needs and arguments for users to participate when designing information systems is elaborated in work describing cooperative and participatory design. Involving the users within different phases of the development process seems, according to many studies, to increase the possibility to produce an information system that is answering to the needs of the users, easier to introduce to new users, and better accepted by the users when implemented. User participation is, however, not always easy to organize for due to time and resource restrictions in real life ISD processes. Public e-service development projects are probably not an exception.

Obviously, it is a more complex task to involve future users in the development of public e-services, compared to ISD efforts of more internal character. The typical questions to ask before user involvement, such as "who are the users?" and "which users should represent the user population?" are more difficult to answer in public egovernment projects. How do we find out what users need when "everyone" in the society is a potential user?

This paper has its origin in the challenge of involving future users in the development of public e-services. The authors conduct action research [3] in an interorganizational e-service development project in public sector in Sweden. The aim of the project is to develop e-services for driving license matters and a web portal where e-services and information will be easily accessible for citizens. The development project was initiated with the dual goals mentioned earlier; i.e. to develop e-services that would be useful for citizens and in the same time redesign the internal business processes and information systems at the involved agencies. The internal efficiency goal tended to dominate from the very beginning of the project, though. An obvious reason for this was that the users were not present at all in the project. Instead, case handling officers from the agencies tried to predict what the citizens wanted. A fact that added complexity to the situation was that the particular e-service under development and the web portal have a main target group of young people who are going to apply for a provisional driving license. The age gap made it even more difficult for the project members to understand what the user needs were. To overcome this problem, the researchers introduced focus groups as a method to meet and talk to citizens and find out their preferences and needs regarding the e-service under development. The method has its pros and cons and this paper discusses how focus groups can be used in e-government projects. The purpose of this paper is, thus, 
to contribute to an improved understanding of how focus groups can be used in order to explicitly utilize citizens' needs and requirements during public e-service development projects.

The paper has the following disposition; after this introduction the role of citizens in e-government projects is discussed and related to literature. In the following section the e-service development project, which serves as our empirical context, is described. Thereafter the focus group method is discussed together with our experiences from using focus groups in this studied project. The paper ends with the main learning outcomes from the study.

\section{The Role of Citizens in E-Government Projects}

Some empirical reporting from e-government projects are more or less success stories [2]. But there are also many statements that consider an important aspect of egovernment projects to be that they often fail. Heeks [11] refers to a Texas county that invested 200000 US dollars in an information system for online building permits that two years after its launch still lacked users. Jupp [12] refers to the "build it and they will come" assumption of e-government projects and states that they often lack real benefits to citizens and are poorly marketed. Graafland-Essers and Ettedgui [9] have shown that a majority of citizens still wants to interact with government agencies in the traditional ways (e.g. face-to-face). All these statements seem to have the importance of understanding the citizen as the future user of the public e-service in common.

When talking about the duality of goal formulations associated with e-government it is also important to distinguish between different kinds of benefit to citizens. Public e-services are often launched as tools to facilitate communication between citizens and agencies. The e-services will make it easier for citizens to access government information and the quality of the services will increase regarding e.g. speed and comprehensiveness. Public e-services are also seen as vehicles to increase democracy and citizens' involvement in the democratic process of decision-making. Key concepts as accessibility, participation, and co-operation are often mentioned to define citizens' benefits. Anttiroiko [2] describes that the issues of participation and democracy have gained increased interest within the e-government field and have according to many people become the ultimate goal for e-government; i.e. to improve interaction between citizen and government [c.f. 10].

Despite this idealistic strive for increased interest in democracy issues, that egovernment is supposed to fulfil, the involvement of citizens in the development projects seems to be low. The National Auditing Office in Sweden discovered, in a recent evaluation of Swedish e-government projects, that internal efficiency was the dominating motive for initiating e-government projects [19]. Goldkuhl [8] describes a development project where an e-service for municipal child care was specified without a citizen-centric view. This lack resulted in a planned e-service where important functions were missing; functions that were critical for the citizen to experience benefits from the use of the e-service. The user perspective in this project 
seemed to emphasise the citizens as senders of information to the municipality, forgetting that the e-service was developed to serve the citizen (ibid.).

When reviewing e-government literature many authors discuss the importance of citizen involvement. Cullen and Hernon [7] report about an extensive study on how citizens involvement is handled within the e-government field in New Zealand. This seems to be an impressive effort, focused on gaining better understanding of citizens' needs for e-government services within a lot of different fields. Anttiroiko [2] describes how the city of Tampere has formulated a vision of citizen participation. The city has developed different channels to communicate with the citizens and get feedback from them. From this information the city has gathered an e-service palette with popular e-services (ibid.). Cook [4] discusses different methods to gather information about American citizens' preferences and requirements of e-government.

All these examples show what a country, a city or a government agency can do to gain understanding of what the citizens want and, thus, focus the e-service development on those areas. However, none of these cases cover how citizens' requirements might be accessed during the actual development of a particular eservice. Instead, they all focus on how understanding of what citizens in general want from e-government can be reached. This is of course important, but this paper questions what happens after this general understanding has been achieved. When the public e-service development project starts, the citizens seem to be forgotten in many projects. There appears to be a gap between the general understanding of citizens' preferences and user involvement during the actual development process.

This lack of user involvement discussions in e-government literature is also observed by Flak et al. [7]. They argue that e-government research needs to find out what the citizens want in order to suggest improved products and services. On the other hand, they assume it to be difficult for citizens to know and express what they want before having been offered the e-service (ibid.). This argument is also used in other kinds of user participation discussions; i.e. that users cannot be creative enough but tend to focus upon the present situation. As we see it, this possible problem is yet another reason for studying how user involvement in public e-service development can be accomplished.

According to our literature review, it seems to be more usual that citizen involvement occurs in early pre-phases of e-government but more rare in e-service development projects. We have, however, found literature reporting on positive exceptions from this situation. There are even some studies that discuss the use of focus groups as a method to get access to citizens' requirements. Lindblad-Gidlund and Nilsson [15] report from the development of an e-service to facilitate communication between school and home (teachers and parents) where focus groups were used in order to catch the parents' opinions regarding their present communication with school and how this would be possibly improved. Albinsson et al. [1] give another example of an e-government development project where focus groups were used to gather information regarding students' needs and thoughts about how public e-services might be generated in a student centric way. In these two examples focus groups were used as a method, but the authors do not report any specific experiences from the method use. This makes it impossible for us to use these studies in order to validate our results, but nevertheless focus groups seem to have been a suitable method in these projects. 
In some of the studies that focus more explicitly upon citizen participation before starting the development of e-services, focus groups is also mentioned as a method to get in touch with citizens. Cook [4] as well as Cullen and Hernon [5] report from studies where focus groups have been a method for information collection. None of the studies mentioned here do, however, discuss pros and cons with focus groups as a method. Instead, the chosen method is only mentioned without any certain motives or arguments. This encourages us to argue that even if there are some recent examples where focus groups are used in order to get a citizen perspective on e-service development, there is still a need to discuss focus groups as a method in public e-service development.

This review of some e-government research efforts on citizen involvement results in the following statements: User involvement in e-government research has not yet been enough studied. There is a lack of knowledge and empirical findings regarding how citizens can be involved in actual e-service development projects. Activities that encourage citizen involvement, reported in literature, seem to be performed in early pre-phases of e-government projects. Citizens are asked what kind of e-services they would like to use, but there are fewer reports on how citizens can be involved during the development of a certain e-service. Bearing these statements in mind, this paper will now describe how we have used focus groups in an e-service development project and what experiences this attempt resulted in.

\section{The Studied E-Service Development Project}

The public e-service development project that we refer to in this paper is a research project concerning inter-organizational e-service development in the public sector in Sweden. The aim of the project is to develop one-stop government e-services for driving license matters as well as a web portal where these e-services and information about the driving license process will be easily accessible for citizens. In this paper the development project of the web portal is focused. The main motive for the portal development is that responsibility for driving license issues in Sweden is divided between several government agencies. It is, thus, difficult for citizens to find information and get in contact with the correct agency. In order to solve these problems a national web portal has been developed. The portal will cover all aspects within the driving license area; providing the citizens with right information, access to e-services and serve as a bridge between the involved responsible government agencies and organizations. The portal will, thus, be a true one stop e-government solution.

The reported project is an action research project with the purpose of both developing and evaluating e-services. The empirical findings presented in this paper was collected during our participation in the development project. The findings have been theoretically grounded and analyzed as well as discussed with the practitioners.

The development project of the e-services and the web portal started prior to the action research project. As mentioned above, the e-service development project initially had no explicit user participation. The development of the e-services for 
driving license matters and the web portal started in a group of representatives from the Sweden's County Administrations (SCoA) and the Swedish Road Administration (SRoA) together with external ISD consultants. The outcome from the development project was not at first anchored in any citizen requirements or explicitly expressed problem. The development group was mainly focused on how the e-services would influence the internal procedures and routines at the agencies. The consultants were left with rather free choices regarding how the e-services should be designed. User requirements were mostly "guessed" (predicted) by the agency officers according to their prior experiences from citizen contacts. When the action research project started to follow the development project, the researchers posed questions about the citizen perspective and how the user requirements were supposed to be caught during the development process. As a solution to this problem we proposed that focus groups should be arranged in order to discuss how young people think about the planned web portal and the e-services. Information gathered from these group discussions was meant to complement the information and experiences from the agency officers in the project, in order to consider if their assumptions about the citizens requirements were valid or not.

\section{Using Focus Groups}

Focus groups have a long history as a data collection method in the marketing field [6]. The method has in recent years become an instrument in the public society to hear "the people's voice". Focus groups are also used as a data collection method by researchers, mainly in social sciences [20]. Morgan [17] describes focus groups as group interviews. A moderator guides the group when discussing decided issues by posing questions that have been formulated in advance. A focus group is always created with a certain purpose; there is a need that the focus group is supposed to fulfill. Focus groups are a feasible tool to gather knowledge and enquiries from different individuals [17]. Different persons possess pieces of knowledge about a certain matter and when these pieces are brought together and discussed the total amount of knowledge increases. When gathering a focus group it is important to be able to declare what the group is supposed to produce.

A focus group often consists of six to eight persons [17], but other authors mention different preferable sizes of the group, ranging from four to twelve persons depending on the purpose of the group. It is an intricate task to choose persons for the focus group. The participants should be picked so that they can contribute to the discussion. It can be difficult to convince persons to join the focus group, they may demand some benefit in return. It is also important to consider which type of data the focus group discussions will result in and how the data can be analyzed afterwards. Data must, thus, be presented in a clear way and be adjusted to the target group. (ibid.)

The moderator who leads the focus group must facilitate that everyone participates and that no one dominates the group. The atmosphere should be friendly in order to encourage everybody to contribute to the discussion and the purpose of the focus group. The moderator is not supposed to insert his or her own opinions into the 
discussion [14], instead the moderator should ask questions to the group. Morgan [17] argues that the focus group can be either structured and unstructured. There are advantages with groups of people knowing each other as well as with groups of strangers. Individuals view issues from different perspectives and focus group is, thus, a suitable method to use in order to understand how different views are constructed and expressed [13] and provide a profound discussion in a certain matter.

In the action research project, two focus groups were arranged, where the participants either had a driving license or were potential drivers (i.e. persons without a license today who planned to take a driving license in the future). When we gathered persons to our two focus groups age was the main factor of selection. We decided to have one group with seven university students (who were more likely to have a driving license) and one group with five high school students (in their second year) who were also pupils at a driving school (and thus in the process of taking a driving license). Main reasons for gathering young persons were that they represent an important target group of the portal and that they possibly would have their own driving license process in close memory or in near future.

Each group was led by two moderators. The main assignment was to discuss early prototypes of the web portal regarding information, e-services and user interface. The assumed outcome was thoughts about information structure and presentation. Public e-services were discussed in general and the e-service for application of provisional driving license in particular. Six of the seven university students had a driving license, which was a conscious choice since Morgan [17] argues that the participants' background should be as homogenous as possible.

The focus groups were introduced by the moderators who presented the e-service development project, the driving license field in general, and the purpose of the focus group meeting. They also described the process of taking a driving license in order for everybody to better understand how a web-portal might be used in these cases. After this background and introduction a brainstorming activity was performed, where the concepts of driving license and electronic identification (which is a necessity for citizen identification in order to use the e-service) were in focus.

In the next phase of the meeting the participants were asked questions in order to discuss information and e-services on the future portal, regarding for example search alternatives and service content. Two main scenarios were used in this discussion; a citizen who already has a driving license and a citizen who is in the process of getting a license. The results from this discussion were then prioritized by the participants regarding the importance of the proposed information content or e-service. This part of the data collection was made by answering a questionnaire where the importance was ranged. Examples of mentioned information content and e-services are; approval terms for the provisional driving license (a permission that everyone who wish to take a driving license in Sweden has to apply for), the driving license process step by step, rules for private driving supervisors (e.g. parents), the compulsory training required to get a driving license, rules for driving license training, costs associated with the driving license, driving license tests (theory and practice), involved government agencies, the driving education curriculum, and time-booking of driving tests.

The next phase of the focus group meeting implied a discussion of how ten driving license concepts were understood by the participants. Discussed concepts were those which could possibly be misunderstood by citizens using a portal because of their 
technical nature. Examples of discussed concepts are; provisional driving license, knowledge test, driving test, risk education, and traffic inspector. The reason to discuss those concepts in the focus groups was to find difficult concepts that need further explanation when used in the portal. The result showed that most of these concepts were hard to understand and the definitions proposed by the participants were more or less incorrect.

The meetings were concluded by evaluation of the low-fidelity prototype of the portal. The participants were asked to focus on information content, information presentation, structure, search alternatives, and navigation logic. The discussions resulted in many comments on the proposed structure and layout. The participants found parts of the content to be irrelevant and missed other information. They had comments on chosen icons and names on bottoms as well as on what actions that were possible to perform in the portal. An important suggestion to improve the use of the portal was to add an personalized e-service called "My driving license", where the citizen could login and find all information regarding his or her driving license process.

As described above the meetings consisted of four phases; an introduction, discussions from two user scenarios and a prioritization of the importance of discussed information and e-services, a conceptual discussion, and a prototype evaluation. All together these phases generated a sufficient set of information that was considered as essential for the future direction of the development project. Some findings showed that the project group had made the right assumptions regarding the citizen requirements, while other findings from the focus groups came as a surprise to the project team. A common aspect of these more unexpected findings were that they represented the attitudes of young persons. An eighteen years old person who has lived his or her entire teenager life as a frequent user of Internet, chatting with friends, using the mobile telephone not only for talking but also for taking photos, sending SMS, and listening to music have certain expectations regarding a government agency's web portal. Their high experiences in these kinds of communication media enable them to take some issues for granted. Therefore, they request and prioritize other functions than a more inexperienced user might do. Some participants did for example mention that they are used to do everything on Internet and that they become irritated when some issues are impossible to handle through this medium. All participants also had very high expectations about what this kind of portal would contain, even when the moderators were asking about a minimum level.

Focus groups have in this empirical case been a method for creating discussion and highlighting different opinions. The atmosphere in the group must be tolerating and everyone has to be allowed to participate in the discussions. The composition of the group is, thus, important. Morgan [17] states that there should be some common characteristics of participants or the participants might have relation to each other prior to the meeting. This might make the discussion climate open-minded and allowing. In the two focus group meetings, we found the aspect of letting everybody express their opinions to be the most important condition for creating a sound discussion climate. A problem that we encountered was that engaging participants for the focus groups turned out to be rather difficult. It was hard to motivate and find incentives for persons to participate without being able to offer them some compensation. Obviously, the fact that we had no budget for such expenses, expect 
offering coffee and cookies, was a mistake. Our experiences indicate that this problem should not be underestimated in future cases.

Our experiences indicate that focus group is a feasible method for gathering citizen opinions and attitudes regarding e-services under development. There are, however, some important aspects to consider in order to gain the most benefits from the method. The preparation and organization before the meetings are of uttermost importance. The meeting must be well designed and thoroughly planned in advance. The introduction, the questions to be asked, the scenarios and concepts to be discussed, etc. all need to be carefully designed. At the same time one must, in the moderator role, have the ability to act upon unexpected state of affairs. We also recommend that the groups should be rather homogeneous [c.f. 17]. Instead of having heterogeneous groups, several groups with for example different life situations can be arranged in order to illuminate different perspectives and view points.

The purpose of the meetings must also be totally clear, both for the development group as a whole and for the person(s) who act as moderators. Otherwise, the scope of the discussions might be too wide or the requested information may not be collected. The preparation, as well as the data analysis after the meeting demands resources, but focus groups as a method requires relatively small resources compared to for example citizen surveys (performed by telephone or questionnaires). On the other hand, this kind of qualitative methods results in views of some citizens' attitudes and needs, not statistically representative data about what citizens as a group really want. This is obviously very important to remember when using data collected from focus groups in e-government development projects. This fact might be considered as a weakness of focus groups, but as we regard it deep "pictures" of some citizens' views are a good way to grasp citizen requirements, compared to total absence of citizens that are a fact in many e-government projects of today. If focus groups are used to a larger extent than in our project, the groups might also function as a way to legitimate and launch the e-service.

We identified that the use of scenarios and low-fidelity prototypes facilitated the discussion in the focus groups. This might be a way to reduce or avoid the situation that the citizens cannot imagine how an e-service would look like [e.g. 7], what would be possible to do, what requirements the user could have in this particular case and so on. The timing of focus groups is an important aspect to consider. As we see it, focus groups can be used in order to collect data in very early stages of e-government development, as was the case in some of the literature examples above [e.g. 2, 5] Focus groups have also turned out to be useful in later stages of e-service development, as in our case. If results from focus group discussions should influence the project's outcome, the method must not be used too late in the development process. On the other hand, focus groups can also be used as parts of the assessment of the developed e-service and, thus, the method can be used in the evaluation phase as well.

Our empirical findings from using focus groups can be related to general user participation research, since collecting citizens' opinions and needs in focus groups might be seen as a special case of user involvement in information systems development projects. Mumford [18] is a pioneer in the field of user participation. She distinguishes between three types of user participation; which imply varying user influence on the outcome; consultative (i.e. user needs influences design decisions 
made by the design team), representative (i.e. affected user groups are represented in the design team), and consensus (all users are involved through communication and consultation). Focus groups, as we have used the method, is closest to consultative user participation.

\section{Conclusions}

After having used focus groups to involve users and collect user opinions from citizens we have found focus groups to be a valuable method to use in public eservice development projects. Though, we do not consider it possible to gather enough citizen representatives to specify all user requirements with the same accuracy as in internal ISD projects in other domains. We have, however, found focus group to be a helpful tool to use when having the ambition of talking to citizens instead of talking about them within the context of e-government development projects.

The planning of focus groups decides whether the focus group meeting will serve as a successful way to get in touch with citizens or as a failure that might increase the distance between citizens and government. The purpose of the meeting must, thus, be clearly stated and the entire session must be carefully planned. This implies that the phases of the meeting should be designed in a way that facilitates the fulfillment of the purpose. Different situations that might occur during the meeting must be estimated so that the moderators are prepared for possible problems. What do we do if the discussion ends, if discussed issues are too far from the purpose, if participants do not get along well, etc. are questions that need to be considered in advance.

The moderator(s) play an important role during the focus group meeting. We have found it successful to be two moderators who then are able to take different roles during the meeting. One can be active and provide the discussion by posing questions while the other can document and observe the situation. These two roles are also possible to alter during the meeting; e.g. being responsible for different phases of the meeting. It is also important that the moderators do not take anybody's side in the discussion or argue for a certain design solution. The moderator has to be objective, otherwise the discussions will probably be biased and influenced. This can be reached in different ways; we suggest that the moderators are not chosen from the design team. Preferably, the moderators should be persons with good understanding of the focused issues but without any personal involvement in the outcome of the development project.

In order to arrange focus group meetings it is essential to find participants who are willing to spend some time discussing a certain issue. This aspect of the method turned out to be the most problematic one in our case. Participants should be chosen so that they represent main target groups of the future e-service. The groups should preferably be arranged according to certain criteria that meet the expectations of the outcome. On the other hand, the development team is relying on the kindness of citizens. No citizen can be forced to participate and many people do not prioritize this kind of activity in a very busy life situation. A key solution to this problem is probably both to convince the citizen that he or she will be an important contributor to the meeting and to offer something in return (to define incentives). The focus groups 
have to be launched in an attractive way and the development project needs to have a budget for focus groups expenses. We do not, however, find it appropriate to "buy" citizens, i.e. even if the citizen is offered something in return he or she should participate because of a real interest in the focused issues.

Creating a sound and open discussion climate during the meeting is essential for the quality of the outcome. Of course every participant is responsible for this, but it is the moderator's main responsibility to ensure that everyone is comfortable during the meeting. A sound discussion climate does not mean that the group should reach consensus regarding each discussed issue. The opinions might vary a lot, but all participants should be able to express their views without being questioned or criticized. The speech time should also be divided between the participants so that everyone gets the same opportunities. No one should be allowed to totally dominate the group and no opinion should be treated as more "true" than others. In order to reach this situation, the moderators have to be sensitive and listen carefully to what happens in the group (not only to what is said). If problems occur the moderators have to pause the discussion and start a meta-discussion about the purpose of the meeting.

An important part in planning the meeting is to prepare questions for the discussion. In our meetings we have used scenarios, low-fidelity prototypes and questions as input to the group. This turned out to be constructive fuel for the discussions. It helped to focus on certain aspects and issues, but it also served as aids to continue to a new phase of the meeting (e.g. leaving the scenarios and starting to evaluate the prototypes).

In order to ensure that the meeting results in useful information about citizens' opinions for the development process, documentation and analysis of the outcome is important. We were taking notes during the meeting and we also used questionnaires during the prioritization which served as documentation afterwards. These notes and questionnaires were then analyzed close to the meeting and a report was written as the final result. In the report both the process and the discussed themes were described and commented by the moderators. This report was presented to the development project. We see potentials in other documentation techniques as well, the meeting would for example be videotaped and/or recorded. The participants could also be requested to write an evaluation report after the meeting, in order to express their experiences and ideas afterwards.

This paper has reported from a first trial of using focus groups to gain better understanding of citizens' needs and requirements in an e-service development project. In future research we find it necessary to further investigate focus group as a method, and develop techniques to support the performance of focus group meetings in public e-service development projects. Experiences from further group meetings could e.g. be gathered together into a more explicit method for this context. As far as our experiences indicate, increasing citizens' involvement by using focus groups during e-service development seems promising.

Acknowledgments. This study has been financially supported by the Swedish Agency for Innovation Systems (VINNOVA), through the VINNOVA programme "Innovative development of cross-boundary public e-services" within the Growth Area E-services in public administration. 


\section{References}

1. Albinsson, L., Lind, M., Forsgren, O., Ozan, H.: Turning the internet around - e-Me: The Students ideal e-Service, eChallenges (e*2006), 25-27 October 2006, Barcelona, Spain (2006)

2. Anttiroiko, A-V.: Towards citizen-centered local e-government - The case of the city of Tampere. In Khosrow-Pour, M. (2004, Eds.). Annals of cases on information technology. Idea group Inc.

3. Baskerville, R., Wood-Harper, A.T.: A critical perspective on action research as a method for information systems research. Journal of Information Technology, (1996) 11(3) 235-46

4. Cook M.E.: What citizens want from e-government. Center for Technology in Government, New York, USA (2000)

5. Cullen, R., Hernon, P.: Wired for well-being: Citizens' response to e-government. A report presented to the E-government Unit of the State Services Commission, New Zealand (2004)

6. Fern, E.F.: Advanced focus group research. Sage Publications, Thousand Oaks (2001)

7. Flak, L.S., Moe, C.E., Sæbø, Ø.: On the evolution of e-government: The user imperative. In Tranmüller, R. (2003, Ed.). Proceedings of EGOV 2003, LNCS 2739, (2003) 139-142

8. Goldkuhl, G.: What does it mean to serve the citizen? - Towards a practical theory on public e-services founded in socio-instrumental pragmatism. In Axelsson, K. and Goldkuhl, G. (2006, Eds.). Proceedings of the International Workshop on E-services in Public Administration, 27-47

9. Graafland-Essers, I., Ettedgui, E.: Benchmarking e-Government in Europe and the US. RAND, Santa Monica (2003)

10. Grönlund, Å.: Electronic government: Design, applications \& management. Idea Group Publishing, Hershey (2002, Ed.)

11. Heeks, R.: Implementing and managing eGovernment. SAGE, London (2006)

12. Jupp, V.: Realizing the vision of e-government. In Curtin, G., Sommer, M., Vis-Sommer, V. (2004, Eds.) The World of E-Government, Haworth Press, New York

13. Kitzinger, J., Barbour, R.S.: The challenge and promise of focus groups. In Barbour, R.S. and Kitzinger, J. (1999, Eds.). Developing focus group research: Politics, theory and practice. Sage Publications, London, 1-20

14. Krueger, R.A.: Moderating focus groups: Focus group kit 4. Sage Publications, Thousand Oaks (1998)

15. Lindblad-Gidlund, K., Nilsson, O.: Everyday communication home and school (echoes) A practical example of a public systems development from a citizen's perspective. In Axelsson, K. and Goldkuhl, G. (2006, Eds.). Proceedings of the International Workshop on E-services in Public Administration, 75-84

16. Lynch, T., Gregor, S.: User Participation in decision support systems development: Influencing system outcomes. European Journal of Information Systems, (2004) 13(4) 286301

17. Morgan, D.: The focus group guidebook. Volume 1, Sage Publications Inc. (1998)

18. Mumford, E.: Consensus systems design: An evaluation of this approach. In Szyperski, N. and Grochla, E. (1979, Eds.). Design and Implementation of Computer Based Information Systems, Sijthoff and Noordhoff, Gromingen

19. Riksrevisionen: Vem styr den elektroniska förvaltningen?, RIR 2004:19, Riksrevisionen, Stockholm. (2004) (Who is in control of the electronic government?) [in Swedish]

20. Vaughn, S., Schumm, J.S., Sinagub, J.: Focus group interviews in education and psychology, Sage Publications, Thousand Oaks (1996) 